\section{Shuttle parts could provide route to cut-price heavy launcher}

\section{Washington}

THE announcement that the Strategic Defense Initiative (SDI) is seeking $\$ 110 \mathrm{mil}$ lion to develop technology for a new heavy-lift launch vehicle has prompted a surge of interest in plans for future satellite launchers. Although there are still no firm plans for a launch system with capabilities superior to the shuttle, the backlog of launches left by the Challenger accident, together with the huge demand expected should a ballistic missile defence system be deployed, is creating pressure for an early decision. Chief among the requirements are increased payload weight and reduced launch costs without sacrificing reliability.

The SDI request is part of a $\$ 2,800 \mathrm{mil}$ lion supplement sought for the current fiscal year defence budget. But the National Aeronautics and Space Administration (NASA) has also been making noises about a future heavy-lift vehicle, and officials there hope that agreement will be reached with the Department of Defense (DoD) jointly to develop an unmanned launcher. It will be only partly reusable and therefore may not meet all SDI requirements.

SDI critics such as the Federation of American Scientists claim that the heavylift technology research effort pre-empts a decision on whether to deploy a missile defence system. DoD replies that it is prudent to have a heavy-launch capability should one become necessary.

In the short term, there are several proposals for a launch vehicle using components of the shuttle system. Such a launcher could be ready in the early 1990 s, and could use existing launch facilities in Florida and California. NASA believes a shuttle-derived vehicle could increase payload weight to low Earth orbit by a factor of three or four compared with the shuttle, bringing the total to $150,000-$ $200,000 \mathrm{lb}$. The cost of a launch would be similar to that of a shuttle launch. A decision to build such a vehicle might, however, delay developing a more advanced fully reusable launcher that some believe will ultimately be necessary for SDI.

Among the shuttle-derived proposals offered to NASA is one from Boeing Aerospace and Hughes Aircraft that might be produced commercially. The 'Jarvis' craft would be capable of putting about $80,000 \mathrm{lb}$ into low Earth orbit; on present plans, it would use two shuttle solid rocket boosters and one shuttle main engine. The payload would be mounted above the external fuel tank used by the shuttle. United Technologies has proposed a design in which the payload would be side-mounted, replacing the shuttle orbiter, on a stack consisting of an external tank and two solid rocket boosters. United says its concept could lift 115,000 lb to low Earth orbit; later versions could be made fully reusable. Martin Marietta also has several design concepts incorporating shuttle components.

To realize the improvements in launch costs and in flight rates considered necessary for SDI, many believe a separate and fully reusable system must be developed. Stanley Lewis of Rockwell International, one of four industrial contractors working
Bangalore

INDIAN scientists are in the final stages of preparation for two major space projects - the launch of the second generation Augmented Satellite Launch Vehicle (ASLV) from India itself and the Indian Remote Sensing Satellite (IRS) from the Soviet Union.

At the same time, efforts are being made to keep the multipurpose domestic spacecraft INSAT-1C ready for launch by

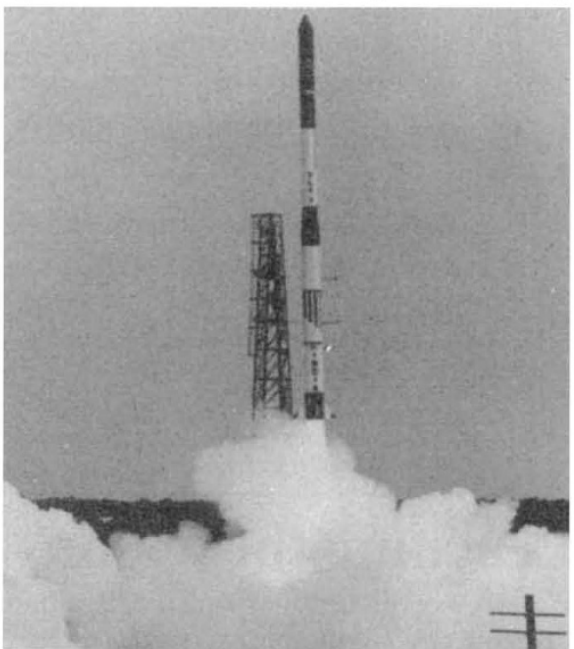

India's first-generation launcher, $S L V-3$.

the European Ariane vehicle in February next year. India is also developing a bipropellant Polar Satellite Launch Vehicle (PSLV) and a liquid fuel Geostationary Launch Vehicle (GSLV), both of which are expected to take off in the late 1980 s or early 1990 s.

The five-stage, solid-propellant-based ASLV, planned for launch in late March from India's eastern missile range on Sriharikota Island, is designed to put a 150$\mathrm{kg}$ spacecraft into a near-Earth orbit. The satellite will carry a payload for the study of gamma rays as well as a package for monitoring the performance of the launch

on the inter-agency Space Transportation Architecture Study, believes complex military satellites for SDI could cost up to $\$ 4,500$ million apiece. Although projections of heavy-lift requirements vary, Lewis believes a fully reusable unmanned launcher capable of lifting up to $150,000 \mathrm{lb}$ into low Earth orbit makes sense for the late $1990 \mathrm{~s}$.

The Space Transportation Architecture Study, which examines the longer-term possibilities and requirements, will be completed in about a year. But SDI is not in a mood to wait, and Defense Secretary Weinberger is now said to want to move "briskly". One way or another, decisions on future launch capabilities are likely to be made before then.

Tim Beardsley

\title{
India's plans for an indigenous launch vehicle still on target
}

vehicle. The launch of this rocket, an improved version of the first-generation SLV-3, was postponed from 1985 because of problems in the motor of the fourth stage.

During its second flight in 1988, ASLV will carry a joint Indian/West German payload for remote sensing with stereoscopic equipment. For the third ASLV flight, the Indian Space Research Organisation (ISRO), in conjunction with the Council for Scientific and Industrial Research (CSIR), will develop a satellite payload to monitor the upper atmosphere.

IRS, to be launched from the Soviet Union, will be lifted into a polar orbit by a vehicle provided by the Soviet Glavcosmos. The satellite will gather data on agriculture, forestry and minerals and will be the first satellite for which India will bear the launch costs. Three earlier satellites were launched free by the Soviet Union.

A major mapping project has been planned for this year covering 183 districts, for which India will depend on data from the US Landsat and the French Spot spacecraft.

Another crucial area in which Indian space engineers are working is in the recovery of rocket boosters. It is proposed to recover the first-stage booster of PSLV with parachutes. This will save India more than Rs400 million. Four launches of PSLV are planned by 1995 . The first stage forms the core booster with 125 tonnes of solid fuel and an additional six strap-on boosters, each with 9 tonnes of solid propellant.

Mitsubishi Electricals of Japan declined some time ago to provide India with LE-5 cryogenic engine technology, but Professor U. R. Rao believes that India would not find it difficult to develop an indigenous launch vehicle to carry a geostatioary satellite, based on cryogenic engines.

Radhakrishna Rao 